\title{
Advances in technology-based training
}

\author{
BRADFORD S. BELL AND STEVE W.J. KOZLOWSKI
}

There is a growing utilization of technology-based training in the workplace. The 2005 State of the Industry Report published by the American Society for Training and Development (ASTD) revealed that in the average organization, technology-based training accounted for 28.1 percent of all training hours in 2004 (Sugrue and Rivera, 2005). The report also revealed that the utilization of technology-based training has almost doubled since 2002 and is projected to further increase to 32.5 percent in 2005 . In this chapter, we examine this trend and explore recent advances in technologybased training. We begin by discussing the environmental factors pushing companies to adopt technology-based training and examine the different technology-based training applications available in the marketplace. We then compare the costs and benefits of technology-based training and identify several factors that can influence its effectiveness. Finally, we conclude the chapter with a few guidelines on how companies can effectively use technology to deliver training and meet their human capital development needs.

\section{Environmental factors influencing technology-based training}

The proliferation of technology-based training has been caused by multiple environmental factors. Globalization, economic pressures, and work-life concerns have combined to create a business environment that demands innovative, flexible training solutions. However, technological advances have helped to position technology-based training applications as practical tools for addressing these demands. In the following sections we briefly discuss each of these factors and how they have influenced the growth of technology-based training. 


\section{Globalization}

Observers have noted that a substantial portion of training costs - upwards of 80 percent - is devoted to simply getting trainees to the training site, maintaining them while there, and absorbing their lost productivity (Kozlowski et al., 2001). For highly decentralized organizations with employees dispersed around the globe, these variable training costs can become prohibitively expensive. Even if an organization has a bottomless training budget, centralized, classroom training is not an efficient means of delivering timely training to a global workforce. Technology enables companies to deliver training to employees almost anywhere and at any time and to be more responsive in today's fast-paced business environment. For example, many large financial institutions that operate on a global scale, such as Citigroup and HSBC, rely heavily on technology to distribute compliance training (e.g., financial regulations, institutional policies and procedures) to their employees located in dozens of countries (Sussman, 2006). Technology-based delivery allows these and other companies with dispersed workforces to bypass many of the costs associated with classroom training (e.g., travel, lodging) and deliver just-in-time learning solutions to their employees.

\section{Economic pressures}

The growing importance of human capital to creating sustained competitive advantage means that, now more than ever, organizations must rely on workplace learning and continuous improvement to remain successful (Salas and CannonBowers, 2001). At the same time, companies face tremendous economic pressures to cut costs and increase shareholder value. The result is that human resource professionals are being asked to do more with less. In the training field this translates into maintaining, or often increasing, a firm's employee development activities while at the same time reducing training expenditures. Technology-based training can help organizations respond to this dilemma. Although technology-based training incurs significant upfront costs (e.g., development, software/hardware), as noted above it also helps organizations reduce variable costs associated with the classroom. The US Army National Guard, for example, saved nearly $\$ 1.6$ million, much of it in travel costs, by converting one of their officer training programs to a distance-learning course (Leonard, 1996). In the past, officers had to travel to Washington, DC for the training, but technology made it possible to transmit the course to a variety of remote sites. Technology-based training can also lead to cost savings in other areas, such as program updating and employees' time off the job. These issues surrounding cost will be discussed in more detail below, but the key point is that technology can be used to help companies lower variable training costs and, therefore, realize a greater return on their training investment. 


\section{Work-life issues}

Research by the Society for Human Resource Management (SHRM) concluded that one of the employment trends anticipated to have the greatest impact on the workplace is the increased demand for flexible work schedules from employees (Schramm and Burke, 2004). Possible causes of this trend include generational differences and the growing number of employees who have childcare and/or elder care responsibilities. (See Chapter 5 for more on the changing family and HRM.) In addition to flexible schedules, many employees increasingly desire flexible work arrangements, such as telecommuting. At JetBlue Airways, for example, 80 percent of all phone reservationists work from their homes in the Salt Lake City area. This perk helps the company successfully recruit and retain individuals for what is a relatively low-wage and typically high turnover job. While flexible work arrangements help employees balance work and life issues, they also create logistical challenges when trying to bring employees together for training. One solution is to use technologybased training to distribute to remote workers so they can complete training off-site and on their own schedule (Burgess and Russell, 2003). For example, CIGNA has embraced technology-based training as an effective and efficient mechanism to deliver continuous education to its dispersed workforce of nurse consultants, many of whom work from home and are based in rural locations. An industry report conducted by Training magazine found that most ( 88 percent) technology-based training activities take place during employees' paid time (Galvin, 2002). However, this figure is likely to be highly variable across companies and we may see more technology-based training conducted on employees' personal time as companies continue to search for ways to maximize employee productivity. In the future this may create a new set of work-life issues for employees to manage.

\section{Technological advances}

While globalization, economic pressures, and work-life issues have forced companies to rethink traditional approaches to training and development, recent advances in computing power and connectivity have probably done the most to position technology-based training as a viable alternative to classroom-based instruction. For a number of years, learning technologies were limited to relatively basic computerbased text programs or video-based instruction. However, recent technological advances have expanded greatly the breadth and depth of training technologies (Salas et al., 2002). Today's high-end technologies offer greater bandwidth, which means that the programs can transmit more information-rich content (e.g., multimedia) and immerse trainees in high fidelity, synthetic training worlds. In addition, advances in communication media (e.g., synchronous audio and video) create greater opportunity for trainer-trainee and trainee-trainee interactivity, opening the door to collaborative and team-based learning. An implication of these advances is that today's high-end technologies can increasingly approximate 
conventional, instructor-led classroom training. This capability, combined with the fact that the media (e.g., compressed video, personal computers, internet) that support these advanced technologies have become more cost-efficient, reliable, and accessible, has led organizations to increasingly utilize technology-based training to respond to their emerging employee development needs. In the next section we examine several of the training technologies currently available in the marketplace.

\section{Training technologies}

There is a wide array of technologies - ranging from more basic to advanced systems - that can be used to deliver training. At the more basic end of the technology continuum are CD-ROM, DVD, and interactive video systems, which offer the capability to integrate text, graphics, animation, audio, and video into a multimedia presentation. One advantage of CD-ROM, DVD, and interactive video over more traditional videotape or audiocassette programs is that the computer-based delivery makes it possible to create programs in which trainees interact with content using a keyboard, mouse, or joystick. Another widely used technology is web-based training. There is tremendous variability in web-based training programs; some simply represent computer-based delivery of text while others integrate multimedia, hyperlinks to references, communication systems, and assessment tools into a hightech instructional experience.

Next in the level of sophistication are electronic performance support systems (EPSS) and intelligent tutoring systems. These systems are more advanced than the typical disk- and web-based programs because they have the capability to deliver highly individualized instruction. An artificial intelligence component analyzes trainee performance by comparing it to an expert model and provides tailored advice and coaching. Finally, at the high end of the technology continuum are distributed interactive simulation (DIS), game-based training environments, and distributed mission training (DMT). All of these systems use synthetic task environments to create "scaled worlds" that immerse trainees in realistic contexts (Schiflett et al., 2004). Moreover, these systems typically offer the capability to conduct real-time, distributed training exercises with multiple participants or teams.

Each of the systems mentioned above is a configuration of technological features. Some of the most common technological features and tools include text, images, video, audio, interactive media, synchronous communication systems, chat, and bulletin boards. Different combinations and variants of these features create the potential for a vast number of unique applications. Thus, it is important to recognize that even within each of the categories mentioned above there is the potential for considerable variability in the configuration of specific systems. Web-based training, for example, can range from very simple, text-based HTML programs restricted to individual users to very advanced multimedia programs that allow for multiuser interactivity and collaboration. 


\section{Benefits of training technology}

The growing adoption of technology-based training in organizations has been fueled largely by the potential practical benefits offered by these systems. However, it is important not to overlook the opportunity to use technology to create stimulating learning experiences. Below we discuss some of most frequently cited benefits of training technology.

\section{Cost reduction}

Most studies have found that technology-based training can deliver a training program for lower cost than more traditional methods. Wisher and Priest (1998), for example, found that using teletraining for an Army National Guard Unit Clerk Course, instead of the traditional classroom training, would lead to savings of $\$ 292,000$ a year. Technology-based training reduces or eliminates many of the variable costs associated with the classroom, such as travel, lodging, meals, materials, and instructor salaries (Welsh et al., 2003). In addition, cost savings can be achieved by using technology to automate many of the tasks involved in course administration, including registration, assessment, and certification. In large organizations, these cost savings multiply across programs and trainees, and can add up to millions of dollars annually. However, it should be noted that these savings can be realized only after the costs of the technology infrastructure are considered. The upfront costs associated with technology-based training (e.g., purchasing hardware/ software, program development) are significant and are frequently discussed as one of the biggest drawbacks of using learning technologies (Welsh et al., 2003).

Accordingly, cost savings are typically achieved only when a program is administered several times and/or to a significantly large number of students. That is, one needs to take advantage of the scalability of technology-based training to amortize the fixed, upfront costs across multiple administrations and a large number of trainees. An important implication is that technology-based training may not produce a positive return on investment for one-shot programs or those with relatively low enrollments.

\section{Reduction in training time}

Another factor that contributes to cost savings is the fact that technology-based training often leads to a reduction in the time that individuals spend in training. Research suggests that putting a training program online can reduce total training time by a quarter to a third. The result is less time off the job and greater employee productivity. The source of this time saving can be found in the ability of trainees to streamline their progression through the training material. That is, technology-based training gives trainees considerable control over many instructional design elements, 
including control over the content, sequence, pace, method of presentation, provision of optional content, and difficulty of instruction. Trainees can use this control to focus their attention on the material they need to learn, spend less time or skip over material they already know, and structure the training in a way that fits their learning style. As we will discuss in more detail below, however, there are some important drawbacks associated with learner control.

\section{Pedagogical capabilities}

While the practical benefits discussed above have been the key drivers of companies' decisions to adopt technology-based training, it is important to highlight the potentially powerful effect that technology can have on learning. Current training technologies offer new and exciting pedagogical strategies that have simply been impossible or impractical in traditional classroom environments. For example, technology can be used to provide trainees with a highly personalized learning experience. Intelligent tutors can be used to monitor trainees' progress and provide individualized instruction that is simply not feasible in the typical classroom environment. Competency assessments can be integrated into technology to provide trainees with personalized feedback that is frequent, immediate, and detailed. Training technology can also be used to immerse trainees in high-fidelity, dynamic simulations that give them an opportunity to practice using their skills and knowledge in realistic situations. A variety of multimedia components can be used to make training more engaging and deliver training through multiple modalities (e.g., visual, audio) to accommodate the preferred learning styles of different trainees. Finally, technology can be used to connect learners to subject matter experts, databases, other learning resources, and one another. Together these and other features of technology-based training can have a positive impact on overall training effectiveness.

\section{Diversity and accessibility}

A less frequently discussed, yet important, benefit involves issues of diversity and access. Some have argued that online learning can increase collaboration among individuals from diverse backgrounds by leveling social barriers. In online environments, the cues that underlie various stereotypes are often either absent or less salient, which may facilitate collaborative learning among individuals drawn from diverse ethnic, cultural, racial, gender, and socio-economic backgrounds. In addition, the flexibility offered by remote learning may provide increased access to individuals who otherwise may be unable to attend training or classes, such as individuals with disabilities (Salas et al., 2002). 


\section{Other benefits}

Although the benefits discussed above are the most frequently cited advantages of technology-based training, there are several other benefits that deserve mention. First, technology-based training makes it possible to deliver a consistent message companywide to all trainees or employees (Burgess and Russell, 2003). For example, when Dow Chemical discovered many of its locations were either not conducting its "Respect and Responsibility" class or delivering inconsistent messages in the training, it turned to technology-based training to provide a standardized, worldwide class (Welsh et al., 2003). Second, technology-based training can help create an environment in which learners have more responsibility for their personal success. Learning technologies can help empower employees to address their skill gaps and manage their career development.

\section{Costs and challenges of training technology}

Despite the numerous benefits discussed above, there continue to be several costs and challenges associated with leveraging technology to deliver training. In this section we review several of these challenges.

\section{Learner choices}

As noted above, technology-based training provides learners with unprecedented control over their learning (DeRouin et al., 2004). Not only can designers incorporate features, such as hyperlinks and menus, that make it possible for trainees to proceed through training in a nonlinear fashion, but also trainees no longer have access to the guidance and support of an instructor or trainer. The result is that trainees are left with complete control over how they approach the training, and research suggests they typically do not make good use of this control (Bell and Kozlowski, 2002a). More specifically, when given control over their learning, most trainees either will exit training before having mastered the subject matter or will practice well beyond the point at which concepts and skills have been learned. The result is that the training is either ineffective or inefficient, both of which are undesirable outcomes.

A related problem concerns trainees' willingness to begin and complete voluntary online courses. For example, a 2001 ASTD/Masie Center study reported that only 69 percent of employees choose to begin compulsory online courses and 32 percent start voluntary online courses (Rossett and Schafer, 2003). In addition, there have been reports from some companies of dropout or non-completion rates as high as 75 percent for their online, self-study courses. These figures stand in direct contrast to the prediction by proponents of technology-based learning that shifting control from the bureaucracy and instructor to the learner would increase trainees' enthusiasm 
and eagerness. Many companies have responded by requiring individuals to pass post-training assessments, tying completion to important rewards (e.g., salary, bonuses), or by employing other strategies designed to force compliance. However, this does not resolve issues surrounding trainee motivation and may lead to other problems. Brown (2005), for example, found that employees who volunteered for an online course spent more time in e-learning. Based on this finding, he concludes "e-learning programs should rely on invitations and marketing rather than forced compliance" (Brown, 2005: 476-477). Thus, the key challenge seems to be how to most effectively capture and sustain the interest of learners in technology-based learning environments.

\section{Social environment and collaboration}

Although some high-end learning technologies enable trainees to engage in very elaborate virtual social exchanges that approximate face-to-face interactions, most learning technologies possess only minimal interactivity and communication capabilities. The result is that in many technology-based training environments trainees may have little or no contact with one another. There is an emerging literature on collaborative learning that suggests that individuals can learn more and learn better by teaching one another. Other training strategies, such as behavior modeling, also rely heavily on social learning. Similarly, some observers have argued that group atmosphere, interactions among trainees and between trainees and trainers, and sense of community offered by traditional, face-to-face instruction are critical for learning (Webster and Hackley, 1997). A high level of interactivity is not necessary in all training programs, but when it is important for learning, the challenge is how to most effectively connect learners in remote environments using communication and group support tools.

A related issue concerns the fact that technology-based training does not provide employees with opportunities to socialize and network with their colleagues. For many employees, training is an opportunity to step away from their day-to-day activities and connect with their co-workers. Training can also provide employees with opportunities to network with management or subject matter experts in their field. It is important to evaluate whether remote learning is consistent with an organization's culture. In organizations that emphasize a "high touch" culture, employees may resist technology-based training because it is inconsistent with the companies' values. This occurred at Starbucks, a company known for its workplace environment and social climate, and caused the company to reassess its move toward using technology-based training. 


\section{Moderating factors of effectiveness}

One may notice that we did not cite training effectiveness as either a benefit or a cost in the discussion above. This is because research that has directly compared technology-based and more traditional, classroom-based delivery of the same course has generally revealed either very small or non-significant differences in student satisfaction and learning outcomes (e.g., Allen et al., 2002; Allen et al., 2004; Russell, 2006). Some proponents have embraced this finding as evidence of the superiority of technology-based training, arguing that the benefit of technology-based training is that it can create the same level of learning as classroom-based instruction at a lower cost. However, we would argue that this finding may be obscuring two important considerations. First, if we are satisfied with the "no significant difference" finding, we are less likely to approach technology-based training as an opportunity to enhance trainees' learning. That is, we avoid fully tapping the unique pedagogical capabilities of learning technologies to create a more powerful and effective learning experience than what can be achieved in the classroom. Second, there is some evidence that the effectiveness of technology-based training is moderated by a number of factors, including the nature of the training content, the delivery technology utilized, and the characteristics of trainees. Thus, the "no significant difference" finding overlooks the fact that technology-based training tends to be a good fit for some training programs and learners, but not others. These more finegrained results are often lost in comparisons of technology versus classroom instruction.

In the following sections we examine several factors that may influence the effectiveness of technology-based instruction. The better we understand these factors and their influence on the success of e-learning initiatives, the better equipped we are to make informed decisions about when learning technologies should and should not be used.

\section{Training content}

How does a company decide which of its training programs should be delivered via technology? Given the attractive practical and financial benefits of technology-based training, many organizations have rushed to put as much of their training as possible online. One result has been a practice known as "repurposing," wherein existing training content from classroom courses is simply mapped onto an existing technology, such as the web. Other companies have been a bit more selective in the courses they transfer online, often restricting technology-based training to courses very heavy in cognitive content (i.e. facts, rules), such as compliance training (e.g., laws, regulations). Still other organizations have focused on creating a specific blend (e.g., 60 percent technology, 40 percent traditional) of different kinds of courses across the company. 
The first approach discussed above is clearly not very strategic. Repurposing overlooks the fact that not all training is going to be a good fit for technological delivery and it also gives little consideration to the type of technology that is best suited for delivering a particular course. For example, many observers have questioned whether technology-based training is an effective means of teaching soft skills, such as interpersonal skills (Welsh et al., 2003). The second approach restricts technology-based training to courses that are heavy in content. This strategy is consistent with research showing that self-directed learning is an effective strategy for cognitive learning outcomes (e.g., knowledge). However, this approach may lead to the underutilization of technology-based training for other types of training (e.g., skill-based) where it might be an effective strategy. The final approach focuses on blending technology and traditional forms of delivery to administer a company's training programs. Recent research suggests there is considerable value in blending technology with traditional instruction not only across a company's training offerings but also within an individual program. Blended learning was rated as the most effective and efficient form of training in a survey of 150 US learning professionals (Anonymous, 2004). In essence, blended learning allows a company to draw on the strengths offered by both technology-based and instructor-led training to optimize training effectiveness.

British Petroleum (BP), for example, adopted a blended learning approach for its global health, safety, and environment (HSE) course. An e-learning course provides employees with the foundation of knowledge on HSE policies before they embark on a one-day, hands-on session on risk assessment and root cause analysis ("Global 'blended' learning at BP," 2003). Companies should avoid, however, trying to adhere to an arbitrary ratio of technology-based and traditional learning. How much or how little of its training a company puts online should be driven by the nature of the training content, the training technologies available, and the fit between the two.

\section{Technological capabilities}

A second factor that has been identified as potentially impacting the effectiveness of technology-based training involves characteristics of the technology. Research has found that the "quality" of the technology often exhibits a relationship with training effectiveness. For example, Webster and Hackley (1997) examined the effect of technological issues on students' reactions to twenty-nine technology-mediated (video) distance learning courses taught at six North American universities. They found that students who reported higher levels of technology reliability and quality had more positive attitudes toward the technology and had more positive attitudes toward distance learning as an educational medium. A second study by Horwath (1999) found that novice e-learners in a virtual classroom became anxious and distracted if the technology failed to respond within fifteen seconds. Although technology reliability remains an important issue, technological advances have greatly reduced unintended interruptions and have created more seamless 
learning experiences. The result is that reliability is not as much of a concern as it once was.

\section{Trainee characteristics}

Training practitioners are increasingly cognizant of the fact that trainees enter a program with a set of personal characteristics that influence how they approach, interpret, and respond to training. Trainees display different learning styles and preferences based on their past experiences, individual characteristics (e.g., age), and dispositions. The result is that instructional designers need to be careful to avoid a "one size fits all" approach to training and consider how to design training to accommodate the needs of different learners.

Some have argued that individual differences are likely to be especially critical in technology-based training environments. Brown (2001: 276), for example, states, "In computer-based training, the learner generally does not experience the external pressures of a live instructor and of peers completing the same activities. Thus, individual differences should be critical determinants of training effectiveness." Fortunately, technology-based training creates an opportunity to adapt instruction to the characteristics of learners to support their strong features and mitigate their weak ones. The challenge, however, is that technology-based training is still in its infancy and we do not yet have a strong grasp of which individual differences are critical in this environment and how best to accommodate them. Yet, based on prior research in other self-directed learning environments, we can identify several individual differences that are likely to influence the success of technology-based instruction.

One important facet is cognitive ability or intelligence. Prior research suggests that individuals high in cognitive ability tend to perform quite well in less structured environments that provide room for self-directed learning. High-ability individuals have the cognitive resources available for monitoring their learning progress and developing effective learning strategies. However, individuals low in cognitive ability can become overwhelmed by the added burden of directing their own learning and typically fare better in more tightly structured lessons. An important implication is that it may be necessary to provide low-ability trainees with additional support (e.g., self-tests) or guidance to help them monitor their progress and utilize the learner control afforded by many technology-based training programs (Bell and Kozlowski, 2002a).

A second potentially important individual difference is goal orientation. There are two types of goal orientations that affect how individuals approach difficult learning tasks. First, a mastery goal orientation is characterized by a desire to increase one's competency by developing new skills and mastering new situations. In contrast, a performance goal orientation is characterized by a desire to demonstrate one's competence to others and to be positively evaluated by others (Bell and Kozlowski, 2002b). A trainee's goal orientation has a number of important implications for how 
he or she approaches training. For example, because mastery-oriented trainees tend to worry less than performance-oriented trainees about their performance and any mistakes they might make, they often have higher and more resilient learning selfefficacy (Kozlowski et al., 2001). In technology-based training, higher self-efficacy may make mastery-oriented trainees more likely to persist through the challenges of self-directed learning and less reliant on an instructor's verbal encouragement. One way to leverage the benefits of a mastery orientation is to design training instructions, goals, and other communications so as to encourage trainees to focus on task mastery and learning, as opposed to performance.

Cognitive ability and goal orientation are two important individual differences, but they are certainly not the only individual characteristics that make a difference in technology-based training environments. Research suggests that trainees with higher levels of prior achievement and knowledge in a subject area perform better in learner control conditions (DeRouin et al., 2004). Trainees who have more previous experience with computers and online learning may experience lower levels of anxiety and greater confidence during training. Trainees who are more conscientious may be more likely to follow instructions and complete the training, and those higher in openness to experience may be more accepting of a novel learning technology. Demographic characteristics, such as age, may also influence individuals' preferences for technology-based learning. Let us hope that future research will detail the role that these and other individual differences play in technology-based training.

\section{Guidelines for technology-based training practices}

Drawing on the review of current research and practice in the area of technologybased training presented above, we conclude this chapter with a few guidelines designed to help companies optimize the effectiveness of their technology-based training initiatives. See Table 3.1 for a list of the guidelines.

\section{Leverage the unique instructional capabilities of technology}

Learning technologies possess unique pedagogical capabilities that have the potential to enhance training effectiveness. This potential can be realized only by moving beyond the practice of repurposing classroom-based training for technological delivery. An alternative approach is needed that involves a detailed assessment of the goals of a training program, identification of the learning experience that will support critical learning processes and facilitate competency development, and careful selection of a learning technology capable of delivering the desired instructional experience (for a more detailed presentation of this approach see Kozlowski and Bell, 2007). Figure 3.1 presents a framework that outlines this alternative approach to technology-based training design. Consistent with recent research that has failed to find that one or more delivery modes (e.g., audio, video) 
Table 3.1 Guidelines for technology-based training

1 Leverage the unique instructional capabilities of technology.

- Assess the goals of a training program.

- Identify the learning experience that will support critical learning processes.

- Carefully select a learning technology capable of delivering the desired instructional experience.

2 Adopt a learner-centered perspective.

- Deliver personalized learning experiences.

- Consider using normative learning curves in an adaptive system.

3 Create a supportive learning environment.

- Create an organizational climate that supports delivering training through technology.

- Create an environment in which technology-based training is aligned with a company's business and human capital development strategies.

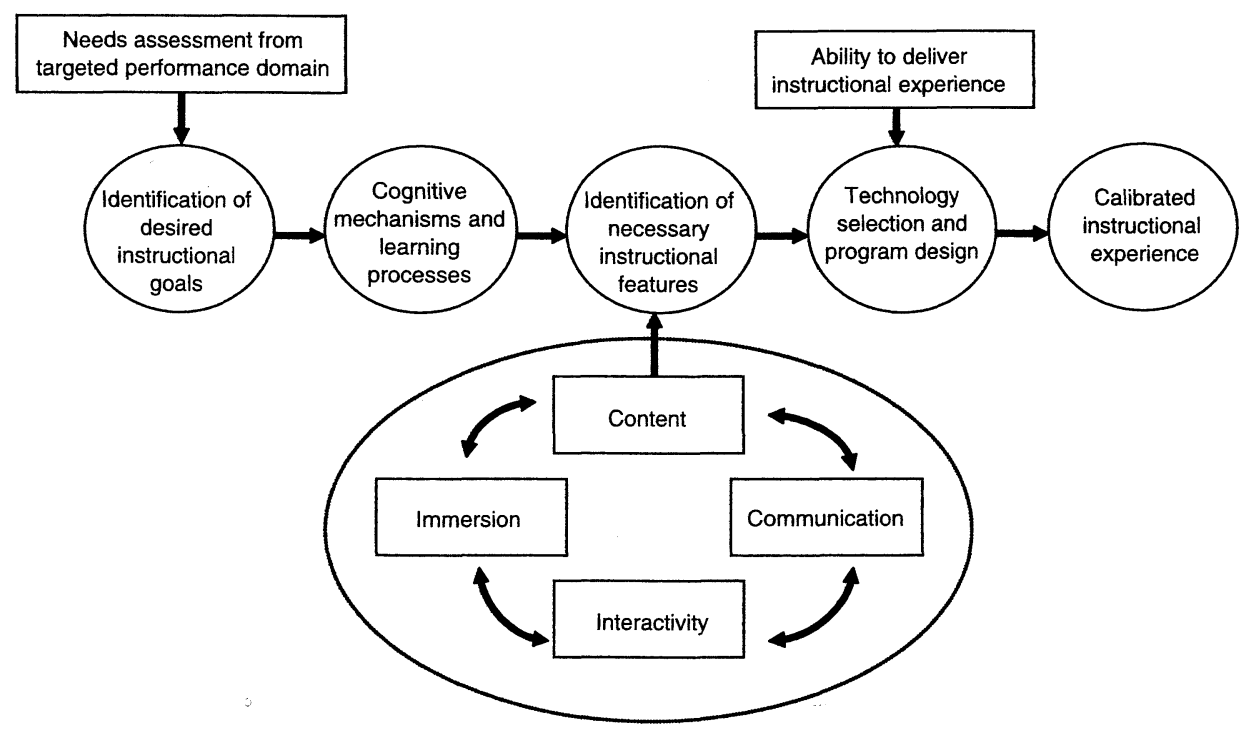

Figure 3.1 A framework for technology-based training design

Source: adapted with permission from Kozlowski and Bell 2002. All rights reserved.

are inherently superior for optimizing learning outcomes (Allen et al., 2004), in this framework training effectiveness is contingent on the alignment of learning considerations with technology selection. Moreover, this framework pushes organizations to think about how the instructional capabilities of learning technologies - in the areas of content, immersion, interactivity, and communication can be leveraged to create training that goes beyond simply replicating the classroom experience. Ultimately, the key point is summarized well by Burgess and Russell 
(2003: 290), "As more organizations and educational institutions adopt distance learning methodologies, it becomes increasingly important to ensure that they are implementing programs that are effective in enhancing employee's skills, rather than simply adopting the latest fad."

\section{Adopt a learner-centered perspective}

Even the best-designed technology-based training program will not optimize learning across all trainees. As we discussed earlier, there are a number of individual differences that have the potential to moderate the effectiveness of technology-based training. If one ignores these individual differences, a specific technology-based training program will respond to the needs of only a select portion of the training population. Moreover, those individuals who have the most to gain from training (e.g., inexperienced trainees, low self-efficacy) are the most likely to be left behind. To respond to this issue, companies need to adopt a learner-centered perspective that focuses on leveraging the capability of technology to deliver personalized learning experiences. To date, however, this technological flexibility has been underutilized. This is due, in part, to the fact that the design of personalized instruction remains a time-consuming and resource-intensive endeavor. For example, some estimates suggest that it takes a team of instructional designers and computer programmers between 200 and 1,000 hours to design an hour of intelligent training. Given these high costs, many organizations avoid personalized instruction because they anticipate a negative return on investment. One promising alternative is a strategy referred to as adaptive guidance (Bell and Kozlowski, 2002a). Unlike most efforts at intelligent tutoring, the design premise for adaptive guidance does not require the intensive development of expert models and complex algorithms. Rather, the approach is benchmarked against normative learning curves which are far easier to develop and deploy in an adaptive system. Adaptive guidance and other advisement strategies represent low-cost, flexible tools for assisting trainees in making effective learning choices in technology-based training, which builds confidence and allows trainees to devote more of their attention to the subject matter of the training program (DeRouin et al., 2004).

\section{Create a supportive learning environment}

One of the most consistent findings to emerge from the training literature is that a supportive learning environment is critical to training effectiveness. A supportive environment is characterized by clear communication of the value of training and management and peer support that cascades from top management buy-in. Research suggests that a supportive environment is also a key success factor in technologybased training. For example, a 2001 ASTD survey of 700 learners from sixteen US companies found that one of the key drivers of trainees' involvement in an e-learning 
program was the support they received from co-workers and managers (Sloman, 2002). In addition, Brown (2005) found that employees with greater workloads spent less time in e-learning. He suggests that companies need to create time and space for employees to participate in e-learning and should market the programs through the value of e-learning offerings.

Companies need to approach the transition to technology-based training as a change management initiative (Welsh et al., 2003). In particular, they need to create an organizational climate that supports delivering training through technology. One important step is to highlight the link between human resources and firm success and communicate the role of technology-based training in developing the company's human capital. There also needs to be a strong sense of accountability surrounding technology-based training. The company needs to be held accountable for creating technology-based training programs that help employees address relevant skill gaps. Management needs to communicate the value of the company's technology-based training initiatives and support employees' participation. Finally, employees need to accept responsibility for using technology-based training as a tool for self-managed competency development and career planning. Ultimately, the goal is to create an environment in which technology-based training is aligned with a company's business and human capital development strategies.

\section{Conclusion}

Powerful forces are afoot that are pushing organizational training out of the classroom and into workplace technologies. Although this shift in training delivery offers cost-savings and other practical benefits, it also offers the potential to revolutionize training effectiveness by making training better targeted and more learner centered and personalized. Companies that realize this potential will be better positioned to leverage their human capital for sustained competitive advantage.

\section{References}

Allen, M., Bourhis, J., Burrell, N. and Mabry, E. (2002) Comparing student satisfaction with distance education to traditional classrooms in higher education: A meta-analysis. American Journal of Distance Education, 16: 83-97.

Allen, M., Mabry, E., Mattrey, M., Bourhis, J., Titsworth, S. and Burrell, N. (2004) Evaluating the effectiveness of distance learning: A comparison using meta-analysis. Journal of Communication, 54: 402-420.

Anonymous (2004) Blended is better. $T+D, 58(11): 52-55$.

Bell, B.S. and Kozlowski, S.W.J. (2002a) Adaptive guidance: Enhancing self-regulation, knowledge, and performance in technology-based training. Personnel Psychology, 55: 267-307.

Bell, B.S. and Kozlowski, S.W.J. (2002b) Goal orientation and ability: Interactive effects on selfefficacy, performance, and knowledge. Journal of Applied Psychology, 87: 497-505. 
Brown, K.G. (2001) Using computers to deliver training: Which employees learn and why? Personnel Psychology, 54: 271-296.

Brown, K.G. (2005) A field study of employee e-learning activity and outcomes. Human Resource Development Quarterly, 16: 465-480.

Burgess, J.R.D. and Russell, J.E.A. (2003) The effectiveness of distance learning initiatives in organizations. Journal of Vocational Behavior, 63: 289-303.

DeRouin, R.E., Fritzsche, B.A. and Salas, E. (2004) Optimizing e-learning: Research-based guidelines for learner-controlled training. Human Resource Management, 43: 147-162.

Galvin, T. (2002) 2002 Industry report. Training, 39(10): 24-73.

Global "blended" learning at BP (2003) Strategic HR Review, 2(6): 4.

Horwath, A. (1999) Novice users' reaction to a web enriched classroom. Virtual University Journal, 2: 49-57.

Kozlowski, S.W.J. and Bell, B.S. (2002) Enhancing the Effectiveness of Distance Learning and Distributed Training: A Theoretical Framework for the Design of Remote Learning Systems. Final Report, Contract No. DAAH 04-96-C-0086, TCN: 00156. Research Triangle Park, NC: Battelle Scientific Services.

Kozlowski, S.W.J. and Bell, B.S. (2007) A theory-based approach for designing distributed learning systems. In S.M. Fiore and E. Salas (eds.), Where is the Learning in Distance Learning? Toward a Science of Distributed Learning and Training. Washington, DC: APA Books.

Kozlowski, S.W.J., Toney, R.J., Mullins, M.E., Weissbein, D.A., Brown, K.G. and Bell, B.S. (2001) Developing adaptability: A theory for the design of integrated-embedded training systems. In E. Salas (ed.), Advances in Human Performance and Cognitive Engineering Research, Vol. 1 (pp. 59-123). New York: JAI Press.

Leonard, B. (1996) Distance learning: Work and training overlap. HR Magazine, 41(4): 40-47.

Rossett, A. and Schafer, L. (2003) What to do about e-dropouts. $T+D, 57: 40-46$.

Russell, T. (2006) The no significant difference phenomenon. Available http:// www.nosignificantdifference.org/ (accessed April 14, 2006).

Salas, E. and Cannon-Bowers, J.A. (2001) The science of training: A decade of progress. Annual Review of Psychology, 5: 471-499.

Salas, E., Kosarzycki, M.P., Burke, S., Fiore, S.M. and Stone, D.L. (2002) Emerging themes in distance learning research and practice: Some food for thought. International Journal of Management Reviews, 4: 135-153.

Schiflett, S.G., Elliott, L.R., Salas, E. and Coovert, M.D. (eds.) (2004) Scaled Worlds: Development, Validation, and Application. Aldershot, UK: Ashgate.

Schramm, J. and Burke, M.E. (2004) SHRM 2004-2005 Workplace Forecast: A Strategic Outlook. Alexandria, VA: Society for Human Resource Management.

Sloman, M. (2002) Breaking through the e-barriers. $T+D$, 56(10): 36-41.

Sugrue, B. and Rivera, R.J. (2005) 2005 State of the Industry Report. Alexandria, VA: American Society for Training and Development.

Sussman, D. (2006) Dividends paid. $T+D, 60: 26-29$.

Webster, J. and Hackley, P. (1997) Teaching effectiveness in technology-mediated distance learning. Academy of Management Journal, 40: 1282-1309.

Welsh, E.T., Wanberg, C.R., Brown, K.G. and Simmering, M.J. (2003) E-learning: Emerging uses, empirical results and future directions. International Journal of Training and Development, 7: 245-258.

Wisher, R.A. and Priest, A.N. (1998) Cost-effectiveness of audio teletraining for the US Army National Guard. American Journal of Distance Education, 12: 38-51. 


\section{SEXUAL HARASSMENT TRAINING FOR PROFESSORS}

Joseph Shenkel works for the HR department in a large university. The vice-president (VP) of HR decided that it would be a good idea for all faculty and staff to receive annual training on detecting and preventing sexual harassment. Joseph was put in charge of the project. He had to determine the content of training as well as the method. Joseph realized that the spectrum of employees covered was broad, with great diversity in ethnicity, age, backgrounds, and education, ranging from those with PhDs to those without high school diplomas.

\section{Related questions}

1 What is it about this context that makes technology-based training especially appropriate or inappropriate?

2 Which training method would be most appropriate?

3 Should the content and/or method be tailored to the employees in this case? 